\title{
Superabsorbent Polymer With Excellent Water/Salt Absorbency And Water Retention, And Fast Swelling Properties For Preventing Soil Water Evaporation
}

\section{Haizhou Tian}

Ningxia University

Sha Cheng ( $\nabla$ cs15101246816@163.com )

Northwest Normal University

Jianghong Zhen

Northwest Normal University

Ziqiang Lei

Northwest Normal University

\section{Research Article}

Keywords: Superabsorbent polymer, Water absorbency, Water retention, Re-swelling property, Water evaporation

Posted Date: December 13th, 2021

DOI: https://doi.org/10.21203/rs.3.rs-1119095/v1

License: (c) (i) This work is licensed under a Creative Commons Attribution 4.0 International License. Read Full License 


\section{Abstract}

Superabsorbent polymers have important applications in many fields, but insufficiency of water/salt absorbency, water retention, and swelling rate limit its application development. Herein, we fabricated HEC-g-P (AA-co-AMPS)/laterite by aqueous solution polymerization, the structure and morphology of the superabsorbent polymer were characterized by FTIR, SEM and TG/DTG. The optimal water absorbency of the superabsorbent polymer were $1294 \mathrm{~g} / \mathrm{g}, 177 \mathrm{~g} / \mathrm{g}$, and $119 \mathrm{~g} / \mathrm{g}$ in distilled water, tap water, and 0.9 $w t \% ~ \mathrm{NaCl}$ solution, respectively. The superabsorbent polymer had good water retention and re-swelling properties at different temperatures, and fast water absorption rate, and reached swelling equilibrium at 5 min. The swelling mechanism of the superabsorbent polymer was explained by the pseudo-second-order swelling kinetics model and Ritger-Peppas model. The effect of the amount of hydrogel on the water evaporation rate in soil was studied, and it had a good effect.

\section{Introduction}

Superabsorbent polymer is a multi-functional polymer material [1]. It has excellent water absorption and water retention performance because of its slightly cross-linked three-dimensional network structure, and a large number of hydrophilic groups, such as hydroxyl and carboxyl groups [2, 3]. It can absorb hundreds times or even thousands times of water higher than its own quality and swell into hydrogel, the absorbed water cannot removable under a certain range of pressure $[4,5]$ and has repeated water absorbency capacity, safe and non-toxic, good processing and use performance. Therefore, superabsorbent polymers have been widely used in agriculture and forestry [6, 7], medical and health [4, 8], adsorption [9-12], construction $[13,14]$ and petrochemical industry $[15]$, etc. In particular, the use of superabsorbent polymer in soil can not only increase water-holding capacity of soil, but also firmly lock rainwater and irrigation water, slowly release stored water in soil to supply water to crops, thereby enhancing soil water retention [16]. It can also promote the formation of soil aggregate structure to improve soil permeability, improve soil structure, reduce the invalid evaporation and deep leakage of soil moisture and nutrients, and improve the utilization rate of water and fertilizer [17]. At present, there are still few reports on the evaporation performance of superabsorbent polymer in soil.

As an important performance factor, the water absorbency of superabsorbent polymer is restricted by many factors, including structure composition, cross-linking density, surface morphology, and solution properties. Therefore, improving the comprehensive properties of the polymer can be considered from the following aspects. I. Introducing diverse hydrophilic groups. According to the literature, although ionic superabsorbent polymer has excellent water absorbency capacity, its gel strength is relatively low after water absorbed. The polymer of non-ionic hydrophilic monomer has low water absorbency, but its water absorption rate is fast, water absorbency is not affected by the external electrolyte, and gel strength is high after water absorbed. If superabsorbent polymer has both ionic hydrophilic groups (carboxyl, sulfonic acid group, tertiary amine group, etc.) and non-ionic hydrophilic groups (hydroxyl, amide group, ester group, etc.), its salt tolerance, water absorption rate, and gel strength will be significantly improved [18]. II. Compound with inorganic components. The strength of inorganic materials is higher than that of 
polymers, and the price is low. However, inorganic hydrogels have some disadvantages, such as structural instability and irreversibility, but the salt resistance is generally better. Therefore, the composite of polymers and inorganic materials can not only improve the gel strength, but also reduce its cost [19, 20]. \. Increase the specific surface area. Increasing the specific surface area of superabsorbent polymers can increase the contact area between water and polymer particles [21], but excessively reducing the particle size of polymer can have the opposite effect. If the superabsorbent polymers have multi-porous structure, it can increase the contact area with water to improve the water absorption rate [22].

Cellulose is a kind of water absorbent material containing multiple hydroxyl groups and has a certain water absorbency capacity. In addition, it has large specific surface area, biocompatible, biodegradable, non-toxicity, low cost and renewable $[8,10]$. AMPS is a strong anion water-soluble monomer with strong hydrophilic groups (amide group and sulfonic acid group), it has good salt resistance, acid and alkali resistance, and hydrolytic stability [21]. In addition, laterite from Lanzhou was used to produce organicinorganic superabsorbent polymer, which could not only improve the water absorption capacity of the polymer, but also reduce the production cost, and promote the regional economic development and resource utilization. Herein, HEC, AMPS and laterite were used as raw materials to fabricate a kind of superabsorbent polymer with excellent water absorption, water retention, re-swelling ability, and swelling rate. The swelling mechanism was also studied through the kinetic model, and the swelling process was more in line with the pseudo-second-order swelling kinetics model, indicating that the swelling process was controlled by chemical absorption. Based on the previous laboratory study of the influence of the ratio of laterite to loess on soil evaporation performance, the mixed soil of laterite and loess with mass ratio of 2:4 was selected, and hydrogels after swelling of superabsorbent polymer were used to prepare soil-based anti-evaporation composite materials to study the performance of hydrogels to inhibit soil water evaporation.

\section{Experimental \\ 2.1. Materials}

Hydroxyethyl Cellulose (HEC),2-Acrylamido-2-methyl-1-propane sulfonic acid (AMPS) were obtained from Aladdin Reagent (Shanghai) Co., Ltd., Acrylic acid (AA) was obtained from Tianjin Damao Chemical Reagent Factory, Sodium hydroxide $(\mathrm{NaOH})$ was obtained from Tianjin Yiwanda Chemical Co., Ltd., N,Nmethylene-bis-acrylamide (MBA) was obtained from Chinese Drug Group Chemical Reagent Co., Ltd., Ammonium persulfate (APS) was obtained from Yantai Shuangshuang Chemical Co., Ltd., laterite was obtained from Lanzhou.

\subsection{Preparation of HEC-g-P (AA-co-AMPS)/laterite superabsorbent polymer}

The dispersed solution was prepared by adding $12 \mathrm{wt} \% \mathrm{HEC}$ and $30 \mathrm{~mL}$ distilled water into a $250 \mathrm{~mL}$ four-mouth flask with mechanical stirring, nitrogen line and condensing tube and stirring at $70{ }^{\circ} \mathrm{C}$ for 45 
$\min$. Then, the temperature was reduced to $50^{\circ} \mathrm{C}$ and $5 \mathrm{~mL}$ aqueous solution containing $0.8 \mathrm{wt} \%$ APS was added under continuous stir. After $10 \mathrm{~min}$, the mixed solution containing AA with a neutralization degree of $70 \%, 30 \mathrm{wt} \%$ AMPS, $0.08 \mathrm{wt} \%$ MBA and different weight percentages of laterite was added. The mixture was heated to $70{ }^{\circ} \mathrm{C}$ and reacted for $3 \mathrm{~h}$. HEC-g-P (AA-co-AMPS) superabsorbent polymer was obtained except not containing laterite. The product was soaked in methanol for $1 \mathrm{~h}$ to remove the unreacted monomer, washed with distilled water for 3 times, and dried in an oven at $60{ }^{\circ} \mathrm{C}$ until constant weight. The fabricated products were crushed and screened for subsequent testing

The structure of Hydroxyethyl Cellulose and the reaction mechanism of HEC-g-P (AA-co-AMPS)/laterite superabsorbent polymer were shown in Scheme 1 and Scheme 2.

\subsection{Preparation of soil-based anti-evaporation materials}

Put $700 \mathrm{~g}$ sand (its function is to simulate the desertification area) into plastic boxes with the same specifications $(20.5 * 13.2 * 6.5 \mathrm{~cm})$, make the sand level in the plastic boxes, add $120 \mathrm{~g}$ distilled water, make the sand wet evenly. The different amounts of fully swollen hydrogel (optimum synthesis conditions) are spread over the sand. Then, a mixture of $200 \mathrm{~g}$ mixed soil ( $\left.m_{\text {laterite }}: m_{\text {loess }}=2: 4\right), 5 \mathrm{wt} \%$ of straw powder and $100 \mathrm{~g}$ of distilled water was uniformly stirred and spread out in a plastic box, respectively.

\subsection{Characterization of Materials}

The infrared spectra of HEC and prepared samples were recorded by using Digilab FTS-3000 Fouriertransform Infrared Spectrometer in the range of $4000-400 \mathrm{~cm}^{-1}$. The solid sample and $\mathrm{KBr}$ were mixed and ground into powder with the mass ratio of 1:100 and transparent sheet was formed by pressing method. The morphological changes of the samples were observed by Zeiss ULTRA plus thermal field emission scanning electron microscopy (SEM). Thermal stability analysis was carried out with TGA-DSC1 synchronous thermal analyzer by Mettler Toledo. Under nitrogen atmosphere, the temperature range was 30-1000 ${ }^{\circ} \mathrm{C}$ and the heating rate was $10{ }^{\circ} \mathrm{C} / \mathrm{min}$.

\subsection{Performance test of superabsorbent polymer 2.5.1 Measurement of swelling behavior}

$0.1 \mathrm{~g}$ dry samples were accurately weighed and immersed in excess distilled water, tap water and $0.9 \mathrm{wt} \%$ $\mathrm{NaCl}$ solution, respectively. After reaching water absorption balance for $4 \mathrm{~h}$, the samples were sipped to remove excess water and weighed. Water absorption ratio is calculated according to formula (1):

$\mathrm{Q}_{\mathrm{eq}}=\left(\mathrm{M}-\mathrm{M}_{0}\right) / \mathrm{M}_{0}(1)$

Where, $\mathrm{M}(\mathrm{g})$ and $\mathrm{M}_{0}(\mathrm{~g})$ are the masses of the sample reaching swelling equilibrium and the dry sample, respectively $[23,24]$. 


\subsubsection{Determination of water retention at different temperatures}

The $100 \mathrm{~g}$ swollen samples were placed in ovens at $25^{\circ} \mathrm{C}, 35^{\circ} \mathrm{C}, 45^{\circ} \mathrm{C}$ and $60{ }^{\circ} \mathrm{C}$, respectively. The samples were placed for $2,4,6,8,10,12,14,16 \mathrm{~h}$ and weighed. The water retention of hydrogels is calculated according to formula (2):

Water retention $(\%)=\mathrm{W}_{\mathrm{i}} / \mathrm{W}_{0} \times 100 \%(2)$

Among them, $\mathrm{W}_{\mathrm{i}}$ is the quality of the sample placed for different time at different temperatures, and $\mathrm{W}_{0}$ is the mass of the fully swollen sample.

\subsubsection{Re-swelling capacity test at different temperatures}

$100 \mathrm{~g}$ fully swollen samples were placed in the oven at $40{ }^{\circ} \mathrm{C}, 60^{\circ} \mathrm{C}$, and $80^{\circ} \mathrm{C}$ until the sample was completely dried, respectively. Then excessive distilled water was added to make it swelled again and weighed, and calculated the water absorption rate [25]. The above process was repeated several times, the water absorption rate is calculated according to formula (1).

\subsubsection{Measurement of swelling kinetics}

$0.1 \mathrm{~g}$ sample under the optimum synthetic conditions was weighed and immersed in excess distilled water. Use a sieve to remove excess water at a set time interval $(1,3,5,8,10,12,15,18,20,25,30,45,60$, $75,90,120,150,180,210$ and $240 \mathrm{~min}$ ) and weighed it. The water absorption rate was calculated according to formula (1).

\subsection{The water evaporation performance test of swollen hydrogel in soil}

Under natural conditions, the mass of the anti-evaporation material was weighed every $2 \varangle 4 \mathrm{~h}$, and data were recorded. The calculation formula of evaporation rate is as follows:

Evaporation rate $=\left(M_{1}-M_{2}\right) / M_{3} \times 100 \%$ (3)

in which $M_{1}$ is the total mass of the anti-evaporation material, $M_{2}$ is the mass of the anti-evaporation material when $t$, and $\mathrm{M}_{3}$ is the total mass of water in the anti-evaporation material.

\section{Results And Discussion}

\subsection{Morphological Analyses}

Figure 1(a), (b) and (c) are SEM images of HEC, HEC-g-P (AA-Co-AMPS) and HEC-g-P (AA-coAMPS)/laterite, respectively. The surface morphology of HEC was relatively flat, smooth and dense. The surface of HEC-g-P (AA-co-AMPS) was rough and appeared many holes. However, the surface of the 
superabsorbent polymer prepared by adding laterite showed rough surface, multiple and evenly distributed pore structure. The pore structure can facilitate the diffusion of water molecules into the threedimensional structure of the superabsorbent polymer, thereby improving its water absorption [26, 27]. It is also indicated that laterite was involved in the polymerization.

\subsection{FTIR Spectroscopy}

In Fig. 1(d), the curve a was the infrared spectrum of HEC, the C-O-C stretching vibration peak (asymmetry and symmetry) at $1036 \mathrm{~cm}^{-1}$ and $915 \mathrm{~cm}^{-1}$ [28], and the plane of $\mathrm{C}-\mathrm{OH}$ at $1384 \mathrm{~cm}^{-1}$, the vibration peak disappeared after the polymerization reaction; the aliphatic stretching vibration peak of C-H at $2925 \mathrm{~cm}^{-1}$ still existed in the curve $b$ and curve $c$ [29]; the $0-H$ stretching vibration peak at $3433 \mathrm{~cm}^{-1}$, increased in intensity compared to the absorption peak in the $b$ curve and c curve [9]; these results indicated that HEC was involved in the chemical reaction. In curve $b$ and curve $c$, the asymmetric stretching vibration peaks of -COO- at $1404 \mathrm{~cm}^{-1}$ and $1402 \mathrm{~cm}^{-1}$ can be observed, respectively; the stretching vibration absorption peak of sulfonic acid groups $\mathrm{O}=\mathrm{S}$ at $627 \mathrm{~cm}^{-1}$ and $669 \mathrm{~cm}^{-1}$, and the vibration absorption peaks at 1642 $\mathrm{cm}^{-1}$ and $1647 \mathrm{~cm}^{-1}$ were the stretching vibration peaks of $\mathrm{C}=0$ in the amide group $[19,30]$, indicated that the polyacrylic acid chain and AMPS have been grafted onto the HEC skeleton. In the curve c, we found the Si-O-Si bending vibration peak of the laterite at $554 \mathrm{~cm}^{-1}$ [20], indicated that the laterite was involved in the polymerization reaction.

\subsection{Thermal Properties}

The TG/DTG curves of HEC, HEC-g-P (AA-co-AMPS) and HEC-g-P (AA-co-AMPS)/laterite are shown in Fig. $1(\mathrm{e})$ and (f). The TG decomposition curve of HEC showed four steps, that is, $25 \varangle 93^{\circ} \mathrm{C}, 93 \varangle 318{ }^{\circ} \mathrm{C}$, $318 \varangle 884^{\circ} \mathrm{C}$, and $884 \otimes 1000{ }^{\circ} \mathrm{C}$, and weight loss was $7.67 \%, 58.36 \%, 20.94 \%$, and $3.76 \%$, respectively. Meanwhile, there were about three peaks of 53,270 , and $884{ }^{\circ} \mathrm{C}$ on the DTG curve, corresponding to the first three stages, indicated the maximum decomposition speed. The thermal decomposition of HEC-g-P (AA-co-AMPS) and HEC-g-P (AA-co-AMPS)/laterite were mainly divided into four processes, with mass loss of $11.09 \%, 46.29 \%, 30.63 \%$, and $2.07 \% ; 12.53 \%, 44.84 \%, 23.64 \%$ and $2.91 \%$, respectively. The first stage occurred before $145^{\circ} \mathrm{C}$, which can be attributed to the decomposition of moisture and unreacted raw materials in the superabsorbent polymer [31]. The main mass loss occurred in the second stage from 145 to $481^{\circ} \mathrm{C}$, when the chain was broken to remove $\mathrm{CO}$ and $\mathrm{CO}_{2}$, and small molecules such as oligomers in the superabsorbent polymer began to decompose [6]. In the third stage, the decomposition of HEC-g-P (AA-co-AMPS)/laterite was much slower than HEC-g-P (AA-co-AMPS). This is due to the elimination of water from the anhydride formed by two adjacent carboxyl groups on the polymer chain and the decomposition of branched chains in the polymer at $481 \otimes 917^{\circ} \mathrm{C}$ [32]. The decomposition of the fourth stage was between 917 and $1000{ }^{\circ} \mathrm{C}$, which was due to the decomposition of polymer backbone and the destruction of the three-dimensional network [33]. Finally, the mass of the remaining samples of HEC-g-P (AA-Co-AMPS)/laterite was $16.09 \%$, which was higher than HEC (9.28\%) and HEC-g-P (AA-coAMPS) (9.92\%). This was due to the partly decomposition of the product and inorganic salts. The results 
of TG/DTG indicated that there was a chemical reaction took place between HEC and laterite, and the addition of laterite was conducive to the improvement of the thermal stability of the product [34].

\subsection{The effects of synthesis conditions on water (salt) absorbency of polymer}

\subsubsection{Effect of HEC content on water (salt) absorbency of polymer}

AA monomer was used as the benchmark for the convenience of research. The influence of HEC content on water (salt) absorbency of superabsorbent polymer is shown in Fig. 2(a). As can be seen that the water (salt) absorption of the superabsorbent polymer showed the same trend in distilled water, tap water, and $0.9 \mathrm{wt} \% \mathrm{NaCl}$ solution, and its water (salt) absorption performance showed a trend of increased first and then decreased with the increase of HEC content, and the water (salt) absorbency reached the maximum when the HEC content was $12 \mathrm{wt} \%$. HEC provides the polymerization skeleton and reaction site in polymerization, which can affect the reaction rate and the molecular weight of the product. When HEC content was low, the number of active sites generated in the system was small, and the monomer reaction was incomplete, which was not conducive to the formation of polymer skeleton and network. However, when the content of HEC was high, the number of active sites increased and the reaction intensified, bringing about the decline of molecular weight of the product, which had an adverse effect on the improvement of its liquid absorption properties.

\subsubsection{Effect of AMPS content on water (salt) absorbency of polymer}

Figure 2(b) showed the effect of AMPS content on water (salt) absorbency of superabsorbent polymer. As can be observed in the figure, as the AMPS content increased from $20 \mathrm{wt} \%$ to $30 \mathrm{wt} \%$, the water (salt) absorption performance of the polymer improved; but water (salt) absorbency decreased when AMPS content was further increased. The reason might be that the increase of AMPS content, the number of hydrophilic groups (- $\mathrm{CONH}_{2},-\mathrm{SO}_{3} \mathrm{H}$, etc.) increased, at the same time, the synergistic effect of the hydrogen bonding between hydrophilic groups and water molecules and between various groups was enhanced [35], thus increasing the water (salt) absorbency. However, when the AMPS content was higher than $30 \mathrm{wt} \%$, there were overmuch hydrophilic groups, the intermolecular hydrogen bond interaction was larger, and the polymer network shrunk, resulting in lower water (salt) absorbency.

\subsubsection{Effect of initiator content on water (salt) absorbency of polymer}

The content of APS is the main factor affecting the length of polymer chain. The effect of APS content on water (salt) absorption performance is shown in Fig. 2(c). When the content of APS was lower than 0.8 $w t \%$, fewer sites of active free radical were produced, which had less initiation effect on the reaction and reduced the molecular weight of the product, resulting in lower water (salt) absorbency of the polymer. 
However, when the content of APS was higher than $0.8 \mathrm{wt} \%$, the number of active free radicals generated increased [36]. This caused the reaction intensified, the chain segments between the cross-linking points of the polymer became shorter, and the network structure of the polymer became more difficult to expand [37]. Therefore, the water (salt) absorbency was lower.

\subsubsection{Effect of cross-linker content on water (salt) absorbency of polymer}

According to Flory theory, cross-linking density has great influence on the water (salt) absorption performance of superabsorbent polymer [5]. Fig. 2(d) shows the influence of MBA content on water (salt) absorbency of the polymer. With the augment of MBA content from $0.04 \mathrm{wt} \%$ to $0.08 \mathrm{wt} \%$, the water (salt) absorbency of superabsorbent polymer increased. This is because more cross-linking points generated for the system, the cross-linking density increased, and the three-dimensional network structure better formed as the increase of MBA content. When the content of MBA was higher than $0.08 \mathrm{wt} \%$, its water (salt) absorption performance decreased, which can be attributed to the excessive MBA increased the cross-linking sites, resulting in the excessive cross-linking density inside the polymer, the shrinkage of network space [38], the extension of polymer chain and the expansion of network structure were hindered [39].

\subsubsection{Effect of neutralization degree of AA on water (salt) absorbency of polymer}

Figure 2(e) shows the effect of the neutralization degree of AA on the water (salt) absorbency of the superabsorbent polymer. When the neutralization degree of AA was less than $70 \%$, the water (salt) absorbency of the superabsorbent polymer increased with the increase of the neutralization degree of AA. However, the water (salt) absorption decreased when the neutralization degree of AA was further increased. After AA was neutralized by $\mathrm{NaOH}$, the $-\mathrm{COOH}$ became $-\mathrm{COO}^{-}$with negative charge. Due to the electrostatic repulsion in the network, the expansion capacity of the polymer was improved. When the neutralization degree of AA was higher than $70 \%$, the excessive $\mathrm{Na}^{+}$in the system would have shielding effect on $-\mathrm{COO}^{-}$, which would reduce the electrostatic repulsion [5] and hindered the expansion of the molecular chain.

\subsubsection{Effect of laterite content on water (salt) absorbency of polymer}

The influence of the laterite content on the water (salt) absorbency properties of the superabsorbent polymer is shown in Fig. 2(f). The laterite content increased from $0 \mathrm{wt} \%$ to $6 \mathrm{wt} \%$, the water (salt) absorbency of the superabsorbent polymer increased and reached maximum at the laterite content of 6 wt\%, and its water absorbency were $1294 \mathrm{~g} / \mathrm{g}, 177 \mathrm{~g} / \mathrm{g}$ and $119 \mathrm{~g} / \mathrm{g}$ in distilled water, tap water, and 0.9 $w t \% \mathrm{NaCl}$ solution, respectively. As the laterite content further increased, the water absorbency decreased [40]. On the one hand, this is because a large amount of $-\mathrm{OH}$ on the surface of the laterite would polymerize with the polymer, strengthened the cross-linking effect, thereby increasing the water-absorbing 
chain and forming more effective water-absorbing network structure. On the other hand, the addition of laterite caused the composite polymer to form more pores, and the water entered the pores by capillary action and diffusion, so that the polymer was sufficiently swollen, and the water absorbency was increased. However, when the amount of laterite added was too much, the laterite content that cannot be effectively grafted increased, and this part of the laterite acted as a physical filling. The role of the chemical bond was weak, and the laterite would be detached from the polymer under the action of water, resulting in network structure collapsed and the water absorbency decreased [41].

\subsection{Performance analysis of superabsorbent polymer}

\subsubsection{Water retention property of superabsorbent polymer at different temperatures}

The water retention properties of the superabsorbent polymer at different temperatures are shown in Fig. 3(a). As the temperature and time increased, the water retention performance of the superabsorbent polymer decreased gradually. The water retention rates were $97.7 \%, 89.8 \%, 70.6 \%$, and $62.6 \%$ after $16 \mathrm{~h}$ at $25{ }^{\circ} \mathrm{C}, 35^{\circ} \mathrm{C}, 45^{\circ} \mathrm{C}$, and $60{ }^{\circ} \mathrm{C}$, respectively. It is reported that the water contained in the superabsorbent polymer can be classified into free water, bound water, and half-bound water. Compared with free water, the water absorbed in the polymer interacted with through the van der Waals force and hydrogen bonding between the water molecules and the hydrophilic groups. This force made the water not easy to lose, so the superabsorbent polymer had a certain water retention property [32, 42, 43]. In addition, the increasing temperature accelerated the movement of water molecules, thereby reducing the interaction between the polymer and the water molecules, resulting in the decrease of water retention capacity of the superabsorbent polymer as the temperature increased [44].

\subsubsection{Re-swelling capability of superabsorbent polymer at different temperatures}

The re-swelling properties of the superabsorbent polymer at different temperatures are shown in Fig. 3(b). As can be seen from the figure, the re-swelling performance of the superabsorbent polymer decreased with the increase of the temperature and re-swelling times. After re-swelling for 5 times, the water absorbency were $832 \mathrm{~g} / \mathrm{g}, 754 \mathrm{~g} / \mathrm{g}$, and $601 \mathrm{~g} / \mathrm{g}$, respectively; reaching $64.30 \%, 58.27 \%$, and $46.45 \%$ of the original water absorbency at $40^{\circ} \mathrm{C}, 60^{\circ} \mathrm{C}$, and $80^{\circ} \mathrm{C}$, respectively [45]. When the swelling was repeated twice at $40{ }^{\circ} \mathrm{C}$ and $60^{\circ} \mathrm{C}$, the water absorbency was higher than the initial value; after that, the water absorbency was decreased. This can be attributed to the sufficient swelling of the polymer network structure, and the impurity ions were removed after the first swelling, resulting in increase in water absorption performance. However, after repeated use for a plurality of times, the main chain structure of the polymer may undergo a certain degree of change, and therefore caused the decrease of water absorption property $[44,46]$.

\section{6. swelling kinetics}


In order to study the water absorption dynamic mechanism of the superabsorbent polymer, the experimental data were fitted with the pseudo-second-order kinetic model and the Ritger-Peppas model. The pseudo-second-order kinetic model and Ritger-Peppas model are represented by equations (4) and (5) respectively:

$t / q_{t}=1 / k_{2} q_{e}^{2}+t / q_{e}(4)$

$\ln \mathrm{F}=\ln \mathrm{q}_{\mathrm{t}}-\ln \mathrm{q}_{\mathrm{e}}=\ln \mathrm{k}+\mathrm{n} \operatorname{lnt}(5)$

Where, $\mathrm{q}_{\mathrm{e}}(\mathrm{g} / \mathrm{g})$ and $\mathrm{q}_{\mathrm{t}}(\mathrm{g} / \mathrm{g})$ are the water absorption capacity of the product at equilibrium time and $\mathrm{t}$ time, respectively. $\mathrm{K}_{2}\left(\mathrm{~g} \cdot \mathrm{mg}^{-1} \cdot \mathrm{min}^{-1}\right)$ is the rate constant of the pseudo-second-order model, $\mathrm{F}$ is the absorption percentage at time $t, k$ is the structure coefficient, and $n$ is the swelling index that determines the type of diffusion [47].

It can be seen from Fig. 3(c) that the superabsorbent polymer absorbed water quickly in the initial 5 min, reached the swelling equilibrium at $5 \mathrm{~min}$, and presented a fluctuation trend after $5 \mathrm{~min}$ [48]. According to the swelling rate curve in the figure, the relationship between $t / q_{t}$ and $t$ can be well linearized, and the linear correlation coefficient $\left(R^{2}=0.99765\right)$, very close to 1 . It showed that the pseudo-second-order kinetic model had a very good fitting result for the swelling behavior of the superabsorbent polymer, the swelling kinetics of the prepared product could obey with the pseudo-second-order equation very well, and the correlation coefficient between the calculated water absorption capacity and the experimental data was relatively high. Compared with the Ritger-Peppas model, the former had a higher correlation coefficient, which indicated that the swelling kinetic of the synthesized superabsorbent polymer was more consistent with the pseudo-second-order relationship.

For swollen hydrogel systems, according to the relative diffusion rate of water into the polymer matrix and the relaxation of the polymer chain, the diffusion mechanism of water molecules can be divided into five types: (1) $n<0.5$, pseudo-fickian diffusion; (2) $n=0.5$, Fickian diffusion; (3) $0.5<n<1$, non-fickian diffusion; (4) $n=1$, Case II transmission diffusion; (5) $n>1$, relaxation diffusion [49]. The equation is suitable for the initial stage of swelling process [35]. As shown in Fig. 3 (d), $n>1$ occurred within 5 minutes of the beginning of swelling process, the movement of the chain controls the absorption rate. At $5 \rrbracket 240 \mathrm{~min}, \mathrm{n}<0.5$, water molecule diffusion was the main factor of swelling [35].

\subsection{Prevent water evaporation performance of swollen hydrogel in soil}

Figure 4 shows the effect of fully swollen hydrogel on the evaporation rate of water in soil. According to previous research in our laboratory, mixed soil $\left(m_{\text {laterite }}: m_{\text {loess }}=2: 4\right)$ and superabsorbent polymer with particle size of $187.5 \otimes 375 \mu \mathrm{m}$ were selected as materials to fabricate soil-based anti-evaporation materials and the effect of hydrogel on water evaporation in soil was tested [50]. Hydrogel had a significant effect on the evaporation of moisture in soil, and the water evaporation rate decreased gradually with the increase of hydrogel content. Generally speaking, when the soil-based anti-evaporation 
materials were placed for $125 \mathrm{~h}$ under natural conditions, the anti-evaporation effect of hydrogel on soil moisture was the most obvious. Compared with mixed soil (without hydrogel), the evaporation rate decreased by $6.19 \%, 12.86 \%, 14.82 \%, 26.68 \%, 31.63 \%, 32.94 \%$, and $34.71 \%$, respectively. When the mass of hydrogel was $100 \otimes 140 \mathrm{~g}$, the evaporation rate was not much different, this is because the soil contains a lot of inorganic components, such as $\mathrm{Al}_{2} \mathrm{O}_{3}, \mathrm{Fe}_{2} \mathrm{O}_{3}$ and $\mathrm{SiO}_{2}$, etc., when the amount of the hydrogel added in the soil was higher, the hydrogel occurred to de-swelling behavior under the influence of the inorganic components, which made the water absorbed by the hydrogel overflow to the surface of the soil, and increased the evaporation rate at a certain degree. This results revealed that the entrapped water in the superabsorbent composite could be released gradually when the soil moisture was decreased to maintain sustainability of the water into the soil and then by plants [51].

\section{Conclusions}

HEC-g-P (AA-co-AMPS)/laterite superabsorbent polymers were fabricated by aqueous solution polymerization, and the FTIR, SEM and TG/DTG were used to characterize the materials. The optimal water absorbency were $1294 \mathrm{~g} / \mathrm{g}, 177 \mathrm{~g} / \mathrm{g}$, and $119 \mathrm{~g} / \mathrm{g}$ in distilled water, tap water, and $0.9 \mathrm{wt} \% \mathrm{NaCl}$ solution, respectively. The superabsorbent polymer had good water retention performance and re-swelling performance at different temperatures: when placed at $60^{\circ} \mathrm{C}$ for $16 \mathrm{~h}$, the water retention rate can still reached $62.6 \%$; and after repeated water absorption at $40{ }^{\circ} \mathrm{C}, 60{ }^{\circ} \mathrm{C}$, and $80^{\circ} \mathrm{C}$ for 5 times, the water absorbency still reached $832 \mathrm{~g} / \mathrm{g}, 754 \mathrm{~g} / \mathrm{g}$, and $601 \mathrm{~g} / \mathrm{g}$, respectively. The water absorption kinetics of the obtained product in distilled water was studied, and the swelling equilibrium was achieved at $5 \mathrm{~min}$. The swelling kinetic mechanism of the superabsorbent polymer was explained by the pseudo-second swelling kinetics model and the Ritger-Peppas model. We used the fully swelled hydrogel to prepare soil-based anti-evaporation composite materials, and studied its ability to inhibit water evaporation in soil. When placed for $125 \mathrm{~h}$ under natural condition, the evaporation rate of the soil-base anti-evaporation materials reduced by $6.19 \%, 12.86 \%, 14.82 \%, 26.68 \%, 31.63 \%, 32.94 \%$, and $34.71 \%$, respectively, compared with the mixed soil ( $m_{\text {laterite }}: m_{\text {loess }}=2: 4$ ), indicating that it had a good application prospect.

\section{Declarations}

\section{Declaration of Competing Interest}

There are no conflicts to declare.

\section{Acknowledgements}

We thank to the program for Changjiang Scholars and Innovative Research Team in University (IRT15R56), the National Natural Science Foundation of China (51863019), Key Laboratory of Ecofunctional Polymer Materials of the Ministry of Education, and Key Laboratory of Eco-Environment Polymer Materials of Gansu Province. 


\section{References}

1. H. Zhang, H. Ren, S. Qian, H. Zhai, Effects of different lignins on absorption properties and pore structure of polyacrylic acid resin, Wood Science and Technology 53(5) (2019) 1001-1014.

2. J. Ha, M. Kim, W. Lee, H. Lee, C. Han, W.G. Koh, D.Y. Ryu, Direct measurement of crosslinked surface layer in superabsorbent poly(acrylic acid), Mater. Lett. 228 (2018) 33-36.

3. D. Qiao, W. Tu, Z. Wang, L. Yu, B. Zhang, X. Bao, F. Jiang, Q. Lin, Influence of crosslinker amount on the microstructure and properties of starch-based superabsorbent polymers by one-step preparation at high starch concentration, Int. J. Biol. Macromol. 129 (2019) 679-685.

4. X. Li, Q. Li, Y. Su, Q. Yue, B. Gao, Y. Su, A novel wheat straw cellulose-based semi-IPNs superabsorbent with integration of water-retaining and controlled-release fertilizers, Journal of the Taiwan Institute of Chemical Engineers 55 (2015) 170-179.

5. Z. Ma, Q. Li, Q. Yue, B. Gao, X. Xu, Q. Zhong, Synthesis and characterization of a novel superabsorbent based on wheat straw, Bioresour. Technol. 102(3) (2011) 2853-8.

6. N. Thombare, S. Mishra, M.Z. Siddiqui, U. Jha, D. Singh, G.R. Mahajan, Design and development of guar gum based novel, superabsorbent and moisture retaining hydrogels for agricultural applications, Carbohydr. Polym. 185 (2018) 169-178.

7. R. Fan, J. Luo, S. Yan, Y. Zhou, Z. Zhang, Effects of Biochar and Super Absorbent Polymer on Substrate Properties and Water Spinach Growth, Pedosphere 25(5) (2015) 737-748.

8. H. Du, W. Liu, M. Zhang, C. Si, X. Zhang, B. Li, Cellulose nanocrystals and cellulose nanofibrils based hydrogels for biomedical applications, Carbohydr. Polym. 209 (2019) 130-144.

9. Q. Li, H. Lu, H. Xiao, K. Gao, M. Diao, Adsorption capacity of superabsorbent resin composite enhanced by non-thermal plasma and its adsorption kinetics and isotherms to lead ion in water, Journal of Environmental Chemical Engineering 1(4) (2013) 996-1003.

10. J. Ma, X. Li, Y. Bao, Advances in cellulose-based superabsorbent hydrogels, RSC Advances 5(73) (2015) 59745-59757.

11. Q. Wang, Y. Wang, L. Chen, A green composite hydrogel based on cellulose and clay as efficient absorbent of colored organic effluent, Carbohydr. Polym. 210 (2019) 314-321.

12. V.P. Mahida, M.P. Patel, Superabsorbent amphoteric nanohydrogels: Synthesis, characterization and dyes adsorption studies, Chin. Chem. Lett. 27(3) (2016) 471-474.

13. X.F. Song, J.F. Wei, T.S. He, A method to repair concrete leakage through cracks by synthesizing super-absorbent resin in situ, Construction and Building Materials 23(1) (2009) 386-391.

14. H.X.D. Lee, H.S. Wong, N.R. Buenfeld, Self-sealing of cracks in concrete using superabsorbent polymers, Cem. Concr. Res. 79 (2016) 194-208.

15. B. Qin, G. Dou, Y. Wang, H. Xin, L. Ma, D. Wang, A superabsorbent hydrogel-ascorbic acid composite inhibitor for the suppression of coal oxidation, Fuel 190 (2017) 129-135.

16. M. Behrouzi, P.N. Moghadam, Synthesis of a new superabsorbent copolymer based on acrylic acid grafted onto carboxymethyl tragacanth, Carbohydr. Polym. 202 (2018) 227-235. 
17. W. Kong, Q. Li, X. Li, Y. Su, Q. Yue, B. Gao, A biodegradable biomass-based polymeric composite for slow release and water retention, J. Environ. Manage. 230 (2019) 190-198.

18. S.Q. Jiang, X.W. Sun, Z.X. Xie, L. Qin, Study on Synthesis and Property of Anti-Salt Super Absorbent Resin, Advanced Materials Research 873 (2013) 683-688.

19. T.S. Anirudhan, P.S. Suchithra, P. Senan, A.R. Tharun, Kinetic and Equilibrium Profiles of Adsorptive Recovery of Thorium(IV) from Aqueous Solutions Using Poly(methacrylic acid) Grafted Cellulose/Bentonite Superabsorbent Composite, Industrial \& Engineering Chemistry Research 51(13) (2012) 4825-4836.

20. W. Zhu, Y. Zhang, P. Wang, Z. Yang, A. Yasin, L. Zhang, Preparation and Applications of Salt-Resistant Superabsorbent Poly (Acrylic Acid-Acrylamide/Fly Ash) Composite, Materials (Basel) 12(4) (2019).

21. Y. Tang, C. Guan, Y. Liu, Z. Zhang, B. Li, L. Zhu, Preparation and absorption studies of poly(acrylic acid-co-2-acrylamide-2-methyl-1-propane sulfonic acid)/graphene oxide superabsorbent composite, Polym. Bull. 76(3) (2018) 1383-1399.

22. H.J. Hong, H. Yu, M. Park, H.S. Jeong, Recovery of platinum from waste effluent using polyethyleneimine-modified nanocelluloses: Effects of the cellulose source and type, Carbohydr. Polym. 210 (2019) 167-174.

23. M.T. Luo, C. Huang, H.L. Li, H.J. Guo, X.F. Chen, L. Xiong, X.D. Chen, Bacterial cellulose based superabsorbent production: A promising example for high value-added utilization of clay and biology resources, Carbohydr. Polym. 208 (2019) 421-430.

24. M. Diao, Q. Li, H. Xiao, N. Duan, J. Xu, Synthesis and adsorption properties of superabsorbent hydrogel and peanut hull composite, Journal of Environmental Chemical Engineering 2(3) (2014) 1558-1567.

25. Q. Li, Z. Ma, Q. Yue, B. Gao, W. Li, X. Xu, Synthesis, characterization and swelling behavior of superabsorbent wheat straw graft copolymers, Bioresour. Technol. 118 (2012) 204-9.

26. S. Fang, G. Wang, P. Li, R. Xing, S. Liu, Y. Qin, H. Yu, X. Chen, K. Li, Synthesis of chitosan derivative graft acrylic acid superabsorbent polymers and its application as water retaining agent, Int. J. Biol. Macromol. 115 (2018) 754-761.

27. S. Fang, G. Wang, R. Xing, X. Chen, S. Liu, Y. Qin, K. Li, X. Wang, R. Li, P. Li, Synthesis of superabsorbent polymers based on chitosan derivative graft acrylic acid-co-acrylamide and its property testing, Int. J. Biol. Macromol. 132 (2019) 575-584.

28. M. Ghasri, A. Jahandideh, K. Kabiri, H. Bouhendi, M.J. Zohuriaan-Mehr, N. Moini, Glycerol-lactic acid star-shaped oligomers as efficient biobased surface modifiers for improving superabsorbent polymer hydrogels, Polym. Adv. Technol. 30(2) (2019) 390-399.

29. G. He, W. Ke, X. Chen, Y. Kong, H. Zheng, Y. Yin, W. Cai, Preparation and properties of quaternary ammonium chitosan-g-poly(acrylic acid-co-acrylamide) superabsorbent hydrogels, React. Funct. Polym. 111 (2017) 14-21.

30. Z. Xu, Q. Fei, X. Zhang, Synthesis of the starch grafting of superabsorbent and high oil-absorbing resin, Journal of Environmental Sciences 25 (2013) S97-S100. 
31. A. Olad, M. Pourkhiyabi, H. Gharekhani, F. Doustdar, Semi-IPN superabsorbent nanocomposite based on sodium alginate and montmorillonite: Reaction parameters and swelling characteristics, Carbohydr. Polym. 190 (2018) 295-306.

32. X. Yu, Z. Wang, J. Liu, H. Mei, D. Yong, J. Li, Preparation, swelling behaviors and fertilizer-release properties of sodium humate modified superabsorbent resin, Materials Today Communications 19 (2019) 124-130.

33. W. Song, J. Xin, J. Zhang, One-pot synthesis of soy protein (SP)-poly(acrylic acid) (PAA) superabsorbent hydrogels via facile preparation of SP macromonomer, Industrial Crops and Products 100 (2017) 117-125.

34. P. Wen, Y. Han, Z. Wu, Y. He, B.-C. Ye, J. Wang, Rapid synthesis of a corncob-based semiinterpenetrating polymer network slow-release nitrogen fertilizer by microwave irradiation to control water and nutrient losses, Arabian Journal of Chemistry 10(7) (2017) 922-934.

35. Y. Zhang, L. Wang, X. Li, P. He, Salt-resistant superabsorbents from inverse-suspension polymerization of PEG methacrylate, acryamide and partially neutralized acrylic acid, Journal of Polymer Research 18(2) (2010) 157-161.

36. F. Wu, Y. Zhang, L. Liu, J. Yao, Synthesis and characterization of a novel cellulose-g-poly(acrylic acidco-acrylamide) superabsorbent composite based on flax yarn waste, Carbohydr. Polym. 87(4) (2012) 2519-2525.

37. Q. Li, J. Liu, Y. Su, Q. Yue, B. Gao, Synthesis and swelling behaviors of semi-IPNs superabsorbent resin based on chicken feather protein, J. Appl. Polym. Sci. 131(1) (2014).

38. K. Zhong, Z.-T. Lin, X.-L. Zheng, G.-B. Jiang, Y.-S. Fang, X.-Y. Mao, Z.-W. Liao, Starch derivative-based superabsorbent with integration of water-retaining and controlled-release fertilizers, Carbohydr. Polym. 92(2) (2013) 1367-1376.

39. K. Hemvichian, A. Chanthawong, P. Suwanmala, Synthesis and characterization of superabsorbent polymer prepared by radiation-induced graft copolymerization of acrylamide onto carboxymethyl cellulose for controlled release of agrochemicals, Radiat. Phys. Chem. 103 (2014) 167-171.

40. A. Adair, A. Kaesaman, P. Klinpituksa, Superabsorbent materials derived from hydroxyethyl cellulose and bentonite: Preparation, characterization and swelling capacities, Polym. Test. 64 (2017) 321329.

41. E. Feng, G. Ma, Y. Wu, H. Wang, Z. Lei, Preparation and properties of organic-inorganic composite superabsorbent based on xanthan gum and loess, Carbohydr. Polym. 111 (2014) 463-8.

42. Z. Wang, A. Ning, P. Xie, G. Gao, L. Xie, X. Li, A. Song, Synthesis and swelling behaviors of carboxymethyl cellulose-based superabsorbent resin hybridized with graphene oxide, Carbohydr. Polym. 157 (2017) 48-56.

43. M. Zhang, Z. Cheng, T. Zhao, M. Liu, M. Hu, J. Li, Synthesis, characterization, and swelling behaviors of salt-sensitive maize bran-poly(acrylic acid) superabsorbent hydrogel, J. Agric. Food. Chem. 62(35) (2014) 8867-74. 
44. J.-P. Zhang, F.-S. Zhang, Recycling waste polyethylene film for amphoteric superabsorbent resin synthesis, Chem. Eng. J. 331 (2018) 169-176.

45. D. Cheng, Y. Liu, G. Yang, G. Hao, Y. Wang, A. Zhang, Preparation of low cost superabsorbent hydrogel by urea and acrylic acid, Mater. Lett. 204 (2017) 16-18.

46. D. Feng, B. Bai, C. Ding, H. Wang, Y. Suo, Synthesis and Swelling Behaviors of Yeast-g-Poly(acrylic acid) Superabsorbent Co-polymer, Industrial \& Engineering Chemistry Research 53(32) (2014) 12760-12769.

47. J.-P. Zhang, F.-S. Zhang, A new approach for blending waste plastics processing: Superabsorbent resin synthesis, Journal of Cleaner Production 197 (2018) 501-510.

48. M. Zhou, J. Zou, X. Guo, Y. Yang, Superabsorbent nanocomposite and its properties, Journal of Macromolecular Science, Part A 56(5) (2019) 496-505.

49. G. Lan, M. Zhang, Y. Liu, H. Qiu, S. Xue, T. Zhang, Q. Xu, Synthesis and Swelling Behavior of SuperAbsorbent Soluble Starch-g-poly(AM-co-NaAMC $\left.{ }_{14} \mathrm{~S}\right)$ Through Graft Copolymerization and Hydrolysis, Starch - Stärke (2019) 1800272.

50. S. Cheng, W. Zeng, X. Liu, J. Zhao, X. Qiu, Z. Lei, Anti-evaporation Performance of Water in Soil of Superabsorbent Resin with Fast Water Absorption Rate, Water, Air, Soil Pollut. 231(6) (2020) 291.

51. H.A. Essawy, M.B. Ghazy, F.A. El-Hai, M.F. Mohamed, Superabsorbent hydrogels via graft polymerization of acrylic acid from chitosan-cellulose hybrid and their potential in controlled release of soil nutrients, Int. J. Biol. Macromol. 89 (2016) 144-51.

\section{Schemes}

Schemes 1 and 2 are available in the Supplemental Files section

\section{Figures}

\section{Figure 1}

Scanning electron micrographs of (a) HEC, (b) HEC-g-P (AA-co-AMPS) and, (c) HEC-g-P (AA-coAMPS)/laterite (6 wt\%); (d) FTIR spectra of a) HEC, b) HEC-g-P (AA-co-AMPS) and, c) HEC-g-P (AA-coAMPS)/laterite (6 wt\%); (e) TG curves and (f) DTG curves of HEC, HEC-g-P (AA-co-AMPS) and HEC-g-P (AA-co-AMPS)/laterite (6 wt\%).

\section{Figure 2}

The effects of synthesis conditions on water (salt) absorbency of SAR. Effect of (a) HEC content, (b) AMPS content, (c) APS content, (d) MBA content, (e) neutralization degree of AA, and (f) laterite content 
on water (salt) absorbency of superabsorbent polymer.

\section{Figure 3}

Performance test of superabsorbent polymer. (a) Water retention and (b) Re-swelling capability at different temperatures, (c) the pseudo-second-order swelling kinetics model and (d) Ritger-Peppas model of superabsorbent polymer in distilled water.

\section{Figure 4}

The effect of the swollen hydrogel quality on evaporation rate in soil.

\section{Supplementary Files}

This is a list of supplementary files associated with this preprint. Click to download.

- Scheme1.png

- Scheme2.png 